\title{
Final results of the Choroid Plexus Tumor study CPT-SIOP-2000
}

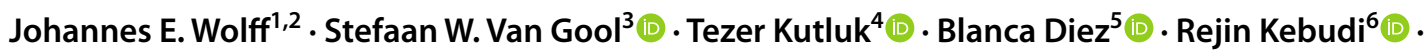

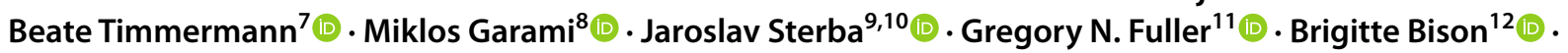 \\ Uwe R. Kordes ${ }^{13}$ (1)
}

Received: 9 November 2021 / Accepted: 31 December 2021 / Published online: 8 January 2022

(c) The Author(s) 2022

\begin{abstract}
Introduction Standards for chemotherapy against choroid plexus tumors (CPT) have not yet been established.

Methods CPT-SIOP-2000 (NCT00500890) was an international registry for all CPT nesting a chemotherapy randomization for high-risk CPT with Carboplatin/Etoposide/Vincristine (CarbEV) versus Cyclophosphamide/Etoposide/Vincristine $(\mathrm{CycEV})$. Patients older than three years were recommended to receive irradiation: focal fields for non-metastatic CPC, incompletely resected atypical choroid plexus papilloma (APP) or metastatic choroid plexus papilloma (CPP); craniospinal fields for metastatic CPC/APP and non-responsive CPC. High risk was defined as choroid plexus carcinoma (CPC), incompletely resected APP, and all metastatic CPT. From 2000 until 2010, 158 CPT patients from 23 countries were enrolled. Results For randomized CPC, the 5/10 year progression free survival (PFS) of patients on CarbEV $(n=20)$ were $62 \% / 47 \%$, respectively, compared to $27 \% / 18 \%$, on CycEV $(n=15)$, (intention-to-treat, HR $2.6, p=0.032)$. Within the registry, histological grading was the most influential prognostic factor: for CPP $(n=55)$ the $5 / 10$ year overall survival (OS) and the event free survival (EFS) probabilities were 100\%/97\% and 92\%/92\%, respectively; for APP $(\mathrm{n}=49) 96 \% / 96 \%$ and $76 \% / 76 \%$, respectively; and for CPC $(n=54) 65 \% / 51 \%$ and $41 \% / 39 \%$, respectively. Without irradiation, 12 out of 33 patients with CPC younger than three years were alive for a median of 8.52 years. Extent of surgery and metastases were not independent prognosticators.

Conclusions Chemotherapy for Choroid Plexus Carcinoma is feasible and effective. CarbEV is superior to CycEV. A subset of CPC can be cured without irradiation.
\end{abstract}

Keywords Choroid plexus tumors $\cdot$ Chemotherapy $\cdot$ Irradiation $\cdot$ Li-Fraumeni syndrome

\section{Introduction}

Choroid plexus tumors (CPT) are rare brain tumors of the choroid plexus epithelium. The age-standardized incidence rate is 1.0 per million, with an incidence peak in the first year of life at 6.1 per million [1]. The WHO classification differentiates between low-grade choroid plexus papilloma (CPPCNS WHO grade 1), intermediate-grade atypical choroid plexus papilloma, characterized by increased mitotic activity (APPCNS WHO grade 2), and high-grade choroid plexus carcinoma, which displays frank signs of malignancy (CPCCNS WHO grade 3) [2]. DNA methylation profiling further segregates three distinct subclass: supratentorial

Uwe R. Kordes

u.kordes@uke.de

Extended author information available on the last page of the article pediatric low-risk CPT $(\mathrm{CPP} / \mathrm{APP})=$ "pediatric $\mathrm{A}$ ", infratentorial adult low-risk CPT $(\mathrm{CPP} / \mathrm{APP})=$ "adult", and supratentorial pediatric high-risk CPT (all CPC, very few $\mathrm{APP} / \mathrm{CPP})=$ "pediatric B" [3-6]. CPC is the typical CPT seen in Li-Fraumeni Syndrome [7].

Treatment recommendations for CPT include multidisciplinary approaches, with maximal surgical resection for all CPT [8-14], followed by chemotherapy [11, 15-21] and radiotherapy [22-24] for high-risk CPT. The prognosis of CPC remains dismal when tumor resection is the only treatment modality, and the role, sequence, and intensity of primary chemotherapy remain debatable [13, 19, 21].

We here report the registry results, and the final results of the first global trial for CPT, which was designed in the late 1990s by an international multidisciplinary pediatric neurooncology collaboration following a metaanalysis [22, 25]. 
The aims were (a) to initiate a registry for the prospective collection of CPT data, (b) to design a multidisciplinary treatment algorithm supporting clinical care by using information from single cases and small series [22, 23, 26], and (c) to perform a randomized interventional study comparing six cycles of carboplatin/etoposide/vincristine (CarbEV) versus cyclophosphamide/ etoposide/vincristine (CycEV).

\section{Methods and materials}

CPT-SIOP-2000 (NCT00500890) was approved by the SIOP scientific committee, the leading institution ethics committee (Regensburg, Germany), local institutional ethics committees, and the German Cancer Society in 2000. Written informed consent was obtained from patients, parents, or appropriate legal guardians in accordance with national laws.

\section{Registry}

Patients with histologically-confirmed newly-diagnosed CPT were eligible for registration, which included all ages, performance status, tumor grade and metastatic status (eligibility criteria listed in Table 1a). Central histology and radiology reviews, as well as Li-Fraumeni syndrome (LFS) testing, were recommended, but not mandatory. Figure 1 depicts the algorithm of registry surveillance for low-risk CPT (non-metastatic CPP and completely resected nonmetastatic APP). Data from patients receiving non-protocol therapy were also collected.

\section{Interventional study}

Patients with either CPC, metastatic disease, or incompletely resected APP were eligible for randomized chemotherapy intervention (Fig. 1; eligibility criteria listed in Table 1b). Open label randomization was provided by the study center. Six cycles of chemotherapy were repeated every 28 days and consisted of etoposide $100 \mathrm{mg} / \mathrm{msq}$ on days $1-5$, with vincristine $1.5 \mathrm{mg} / \mathrm{msq}$ on day 1 . The third drug was randomized to either carboplatin $350 \mathrm{mg} / \mathrm{msq}$ on days 1 and 2 (Supplemental Fig. 1a: CarbEV) or cyclophosphamide $1 \mathrm{~g} /$ msq on days 1 and 2 (Supplemental Fig. 1b: CycEV). Radiotherapy was proposed after two cycles of chemotherapy and restricted to patients that were at least 3 years of age: local fields with $54 \mathrm{~Gy}$ administered in 30 fractions $(1.8 \mathrm{~Gy} / \mathrm{frac}-$ tion) were prescribed for non-metastatic CPC, APP with residual tumor and metastatic CPP. Craniospinal fields of $35.2 \mathrm{~Gy}$ in 22 fractions (1.6 Gy/fraction) with a local boost of up to a total of $54 \mathrm{~Gy}$ for primary tumor and $49.6 \mathrm{~Gy}$ for metastases (both with $1.8 \mathrm{~Gy} /$ fraction), were prescribed for patients with metastatic CPC and APP (Supplemental Table 1a, b).

Feasibility of the study was tested in a pilot phase completed in 2005. The primary objective of the trial was Overall Survival (OS) time (Table 1c). Performance status at diagnosis was graded on a 1-5 level scale (Table 1d). Toxicity was documented in a study-specific grading system (Supplemental Table 2). Statistical analyses were performed in SPSS version 18 (IBM), and GraphPad Prism version 7.00 (GraphPad Software, La Jolla, California, USA, www. graphpad.com). Survival curves were estimated by the Kaplan-Meier method and compared between histologies. Overall survival (OS) was calculated from time of histological diagnosis until death. Event free survival (EFS) was calculated from time of histological diagnosis until tumor progression, second malignancy, death, or date last seen (censored). Progression free survival (PFS) was calculated from time of histological diagnosis to disease progression, death, or date last seen (censored).

\section{Results}

\section{Registry (Consort Diagram 1, Fig. 2a)}

173 patients were screened from 85 institutions across 23 countries from 05-Jan-2000 until 22-Jan-2010. The database was locked for this analysis in 2020. Central review excluded 15 tumors from the analysis as non-CPT (4 ATRT, 2 lowgrade glioma, 1 ependymoma, 2 medulloepithelioma, 2 pineal non-CPT, 1 cribriform neuroepithelial tumor, 3 undeterminable). CPT were upgraded in 12 and downgraded in 17 cases. In 3 cases a local non-CPT diagnosis was revised to CPT. After this review, 158 patients ( 77 females, 81 males) were included for further analyses, median follow-up for these were $7.4(0.2-17)$ years; pathology central review was available in 138 patients (further details: Fig. 2a, b).

The median age at diagnosis for all patients was 1.7 years (0.01-45.6); that for patients with CPP $(\mathrm{n}=55)$ was 2.7 years, for APP $(n=49) 0.7$ years, and for CPC $(n=54)$ 2.1 years. Demographical and clinico-pathological variables are summarized in Table 2. Performance status on the 5 -level scale was documented in 46 patients: $20 \%$ were in level $1,56 \%$ in level 2, 22\% in level 3, and $2 \%$ in level 4 or 5 . Values did not correlate with histology or outcome.

LFS testing was performed for only 9 patients, which was prompted by positive family history in three, and detected pathogenic TP53 mutations in 1 APP (c.743G $>$ A; p.R248Q) and 6 CPC (c.818G >A, p.R273H; codon 1704 bp del leading to stop in codon 173 ; c.847C $>$ T, p.R283C; c.356C $>\mathrm{G}$, pA119G; c.742C > T, p.R248W; mutation not communicated in one). LFS was suspected, but not tested, in one patient with CPC who developed subsequent glioblastoma and 
Table 1 CPT-SIOP-2000 inclusion and exclusion criteria, outcome, performance status

(a) Eligibility Criteria for Registry

Inclusion

(1) Local diagnosis of CPT

a. Choroid plexus papilloma (ICD-O 9390/0)

b. Atypical choroid plexus papilloma (ICD-O 9390/1)

c. Choroid plexus carcinoma (ICD-O 9390/3)

(2) Slides sent for pathology reference review

Exclusion $\quad$ (1) Patient or legal guardian does not consent to enrollment with electronic data processing or sending of tumor slides to the pathology reference center

(b) Eligibility Criteria for Randomized Study Intervention Chemotherapy

(1) The first registration on the study was completed
(2) The pathology reference center has confirmed the receipt of histological slides
(3) Postoperative MRI imaging has been performed and the results are available
(4) Any of the High-Risk CPT criteria are met (Fig. 1)
(5) The chemotherapy start criteria are met
(6) The agreement of the patient or legal guardian has been documented according to local guidelines
(1) Previous irradiation or chemotherapy
(2) Patient or legal guardian does not agree with treatment or randomization
(3) Clinical start criteria for the planned treatment as outlined in treatment modification guidelines are not met
(4) The protocol did not pass the local center required approvals, such as Ethics Committee or scientific review
(5) Previous antiangiogenic therapy
(6) Previous immunotherapy

(c) Objectives and outcome definitions

Survival times

Primary Objective: Overall Survival (OS)

Time from histological diagnosis until death, or the date last seen (censored)

Secondary Objective: Progression Free Survival (PFS)

Event Free Survival (EFS)

Time from histological diagnosis to disease progression or death, or the date last seen (censored)

Time from histological diagnosis until tumor progression, second malignancy, death, or the date last seen (censored)

Response evaluation

Complete response (CR)

No evidence of tumor

Partial response (PR)

Remaining evidence of tumor, with tumor size in cross-sectional area $\leq 50 \%$ of pretreatment value in all known tumor locations;

Stable disease (SD)

Tumor size $>50 \%$ and $\leq 125 \%$

Progressive disease (PD)

Tumor size $>125 \%$ of pretreatment value in any individual tumor location or new lesion

(d) Performance status

Level 1

Level 2

Level 3

Level 4

Level 5 normal activity, no disabilities

minor disability, not requiring additional assistance

age-related activity greatly reduced

bed-ridden, requiring nursing care

intensive medical care, moribund

WHO definitions [2]. • Choroid plexus papilloma: Delicate fibrovascular connective tissue fronds are covered by a single layer of uniform cuboidal to columnar epithelial cells with round or oval, basally situated monomorphic nuclei. Mitotic activity is extremely low. Brain invasion, high cellularity, necrosis, nuclear pleomorphism and focal blurring of the papillary pattern are unusual, but may occur. CPP closely resembles nonneoplastic choroid plexus, but cells tend to be more crowded, elongated or stratified instead of the normal cobblestone-like surface. • Atypical choroid plexus papilloma: A choroid plexus papilloma with increased mitotic activity $\left(\geq 1 \mathrm{mitosis} / \mathrm{mm}^{2}\right.$; equating to $\geq 2$ mitoses per 10 randomly selected high power field of each $0.23 \mathrm{~mm}^{2}$ ). Up to two of the following four features may be present, but are not required: increased cellularity, nuclear pleomorphism, blurring of the papillary pattern, areas of necrosis

Choroid plexus carcinoma: Malignant epithelial neoplasm of the choroid plexus that shows at least four of the following five features: frequent mitoses, increased cellular density, nuclear pleomorphism, blurring of the papillary pattern with poorly structured sheets of tumour cells, necrotic areas

${ }^{a}$ Chemotherapy start criteria White blood cell count: $>2000 / \mu \mathrm{l}$; platelet count: $>85,000 / \mu \mathrm{l}$; serum creatinine: in normal range; pregnancy test: negative (women of childbearing potential); audiology: hearing loss less than $30 \mathrm{~dB}$ at $3000 \mathrm{~Hz}$ 


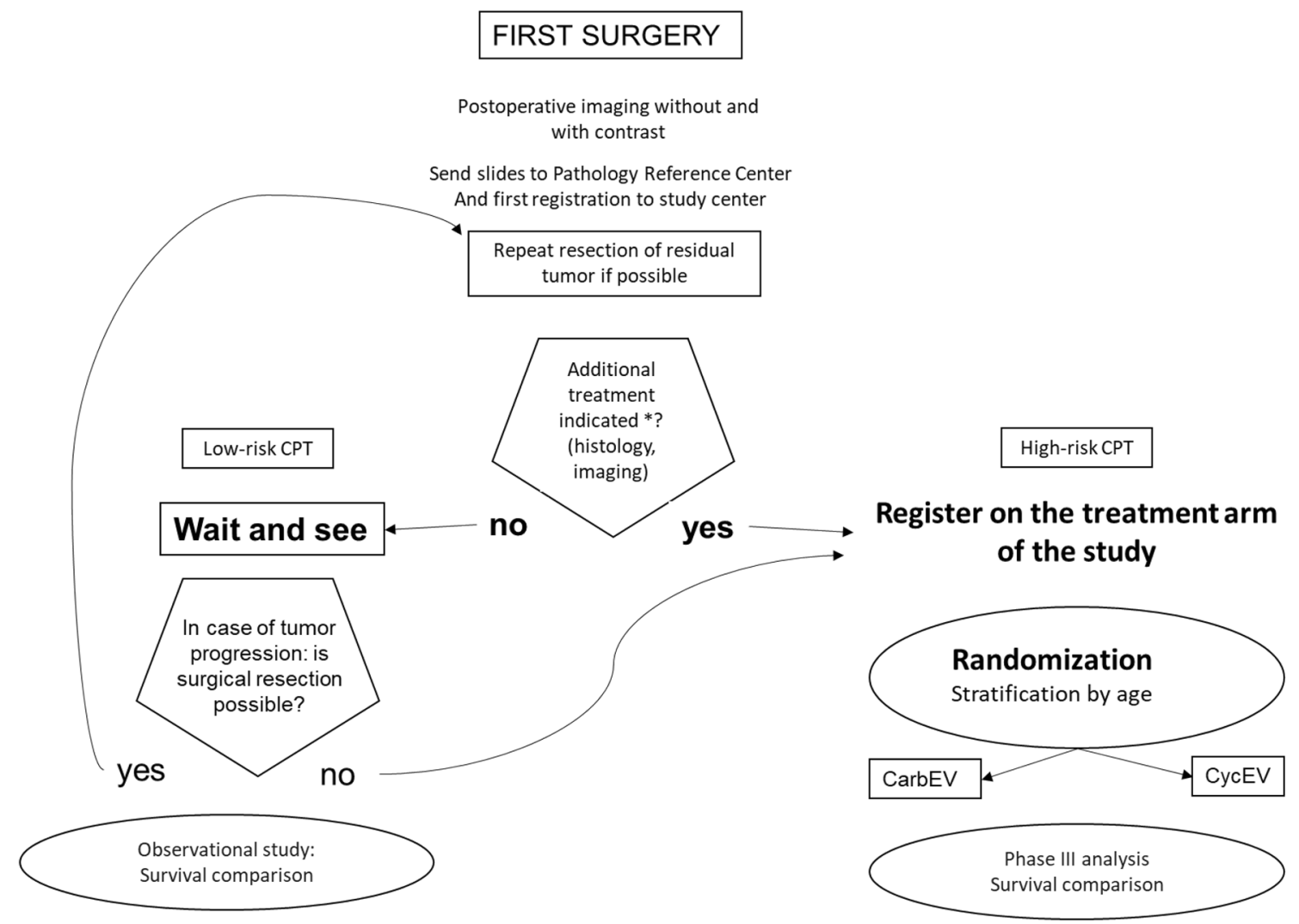

* Additional treatment indicated: Criteria for Chemotherapy in High-Risk CPT

\begin{tabular}{|c|c|c|c|}
\hline $\begin{array}{c}\text { Histology } \\
\text { (ICD-0) }\end{array}$ & Metastases & $\begin{array}{c}\text { Residual Tumor (always } \\
\text { consider second look surgery) }\end{array}$ & Additional treatment \\
\hline CPP (9390/0) & No & Regardless & No \\
\cline { 2 - 4 } & Yes & Regardless & $\begin{array}{c}\text { Yes, consider surgery } \\
\text { of metastases }\end{array}$ \\
\hline APP (9390/1) & No & No & No \\
\cline { 2 - 4 } & No & Yes & Yes \\
\cline { 2 - 4 } & Yes & Regardless & Yes \\
\hline CPC (9390/3) & Regardless & Regardless & yes \\
\hline
\end{tabular}

Fig. 1 CPT-SIOP-2000 algorithm for surveillance and intervention allocation. The original flow chart shows the overall design of the observational registry for low-risk CPT and the interventional chemotherapy study for high-risk CPT. High-risk CPT criteria are listed. These defined the indications for chemotherapy with randomized

malignant hemithorax tumor, and in another patient with APP who had a previous periorbital rhabdomyosarcoma.

Sotos syndrome was diagnosed in one patient with APP. Other co-morbidities were univentricular heart in 1 CPC patient, ureteral duplication in 1 CPP patient, ectopic
CarbEV and CycEV (Supplemental Fig. 2) and radiotherapy, with separate indications for volumes and doses (Supplemental Table 3). The protocol design did not include cross-over between CarbEV and $\mathrm{CycEV}$ arms for non-responders

kidney in 1 APP patient, and demyelinating disease in 1 APP patient.

Available tumor volumes did not differ amongst the CPT subgroups in this cohort (median for all $=53 \mathrm{ml}$ ). $80 \%$ of all CPT were located in the lateral ventricles (94\% of CPC, $84 \%$ 
of APP, $64 \%$ of CPP); location in the fourth ventricle was more common in older patients $(15 / 19$ CPT $>3$ years versus $4 / 19 \mathrm{CPT} \leq 3$ years), and less frequent for high-grade tumors (4\% of CPC, $6 \%$ of APP, $26 \%$ of CPC). Only 1 CPC arose in the third ventricle (Table 2).

At initial staging, 134 patients had localized disease, and 19 had metastatic disease (3 CPP, 5 APP, 11 CPC). Of the 19 patients with metastatic disease, 2 were identified on the basis of positive CSF cytology only, 1 patient had intracranial metastases, 8 patients had spinal metastases, and 6 patients had generalized leptomeningeal disease. For 2 patients with metastatic disease the location was not documented. Staging data were not available in 5 patients. Non-metastatic tumors were more commonly completely resected.

Histological grade was the single most prominent prognostic variable (Fig. 3a,b). The 1,5 , and 10 year OS were as follows: CPP $(\mathrm{n}=55)$ : $100 \%, 100 \%, 97 \%$; $\operatorname{APP}(\mathrm{n}=49)$ : $100 \%, 96 \%, 96 \%$; CPC $(\mathrm{n}=54) 83 \%, 65 \%, 51 \%$. The 1 , 5, 10 year EFS were: CPP: $100 \%, 92 \%, 92 \%$; APP: $90 \%$, 76\%, 76\%; and CPC: $68 \%, 41 \%, 39 \%$. Two patients with CPP experienced malignant progression to CPC and died of progressive disease 5.6 and 13.1 years after primary diagnosis, respectively. One instance of malignant progression occurred in an APP patient. APP patients younger than 2 years of age at diagnosis had significantly higher higher PFS and OS compared to older APP patients (Fig. 3c, d).

For 86 CPT (30 CPP, 25 APP, 31 CPC) a nuclear p53 labeling index was determined and subsequently correlated with grade: 2/30 CPP were positive (index 10\%), 6/25 APP were positive (index $\leq 30 \%$ ), and 19/31 CPC were positive (index 10-90\%). All CPT with a p53 labeling index over $35 \%$ were CPC. Nuclear p53 labeling was assessed in 4 of 7 patients with LFS: the index was $0 \%$ in 2 patients, $10 \%$ in one patient, and $50 \%$ in one patient. There was no prognostic relevance of p53 labeling within any of the histological groups. Methylation profiling [3, 5, 6] was available for 36 patients, with classification results as follows: pediatric $\mathrm{A}$ in 9 (4 APP, 5 CPP); pediatric B in 25 (3 CPP, 8 APP, 14 CPC); and adult in 2 CPP. One of the three low-grade referencereviewed CPT with subsequent malignant transformation was a CPP that classified into the high-risk pediatric subgroup B by methylation profiling.

\section{Surgery}

Complete resection was documented in 98 patients, partial resection in 56, and biopsy in 4 patients. Extent of surgery did not correlate with demographic variables or primary tumor location, but complete resection was achieved less frequently in CPC compared to APP and CPP (42\% versus $69 \%$ and $77 \%$, respectively: $p=0.0032$ ), and the average size of completely resected tumors was significantly smaller than those which were only partially resected: $34 \mathrm{~cm}^{3}$ (range $0.5-184$ ) versus $76 \mathrm{~cm}^{3}$ (range 12-415) (Mann Whitney test: $\mathrm{p}=0.003)$. The prognostic impact of complete resection on survival of all CPT appeared significant for EFS and borderline for OS: the five-year EFS and OS rates were $82 \%$ (CI95\% 72-88) and 89\% (CI95\% 80-94) versus 64\% (CI95\% $50-75)$ and $81 \%$ (CI95\% 68-89) after complete resection versus less than total resection. However, these differences were confounded by the histological grade. When analyzing within each histological group, there was no significant benefit from surgery for PFS, EFS or OS (for CPC: Supplemental Fig. 2).

\section{Radiotherapy}

Following at least two cycles of chemotherapy, 30 patients with CPC and 8 with APP received irradiation. One child with CPP was irradiated because of a local diagnosis of CPC. Eleven patients with CPC received craniospinal irradiation plus local boost (median age at irradiation: 5.9 years, range 3-21.2). Nineteen received local radiotherapy (median age 5.6 years, range 1.5-18.6). The 2-year EFS without and with radiotherapy was $47 \%$ (CI95\% 27-65) versus $76.5 \%$ (CI95\% 56.9-88, $\mathrm{p}=0.23$ ), respectively. The 2-year OS without and with radiotherapy was 55\% (CI95\% 34-72) versus $96.7 \%$ (CI95\% 78.7-99.5), respectively. This difference did not reach statistical significance (Log-rank test: $\mathrm{p}=0.052$ ). Among APP patients, for irradiated versus not irradiated, the 5 year OS/PFS was $75 \% / 63 \%$ versus $100 \% / 92 \%$, respectively.

\section{Chemotherapy in high-risk CPT (Consort Diagram 2, Fig. 2b)}

Chemotherapy was provided to $87 \mathrm{CPT}$ comprising $8 \mathrm{CPP}$, $24 \mathrm{APP}$, and $55 \mathrm{CPC}$ (including the three $\mathrm{CPC}$ arising via malignant transformation): $35 \mathrm{CarbEV}, 41 \mathrm{CycEV}, 11$ other (site decision). 6 of $18 \mathrm{CPP} / \mathrm{APP}$ with incomplete resection had an OR (CR + PR) after two cycles of chemotherapy. 35 patients started CarbEV or CycEV after complete resection; none of these experienced tumor progression during the first two cycles. Twelve of 33 patients with CPC younger than 3 years of age at diagnosis were treated with chemotherapy only (without radiation) and are alive with a median followup of 8.52 years $(0.86-12.79)$.

\section{Carboplatin versus cyclophosphamide randomization}

As per intention-to-treat (ITT) 20 CPC were randomized for CarbEV and 15 for CycEV. The study arms had matching clinical values gender (equal), extent of resection (GTR in $50 \%$ each), metastases ( $n=3$ in CarbEV, $n=2$ in CycEV), 
(a)

173 CPT

15 excluded by reference histology

\section{8 (55 CPP, 49 APP, 54 CPC)}

78 CPT allocated to surveillance

74 CPT allocated to intervention

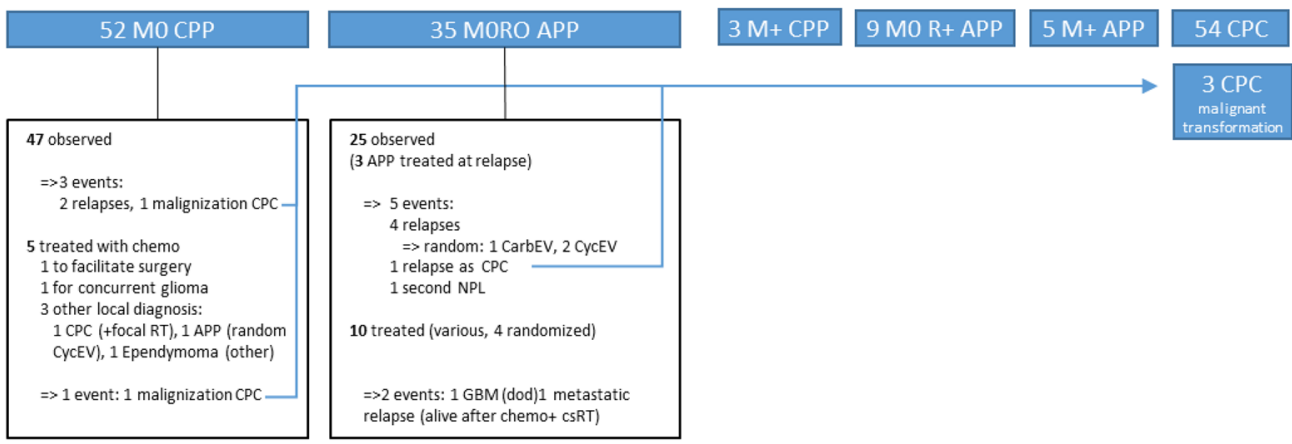

(b)

74 CPT allocated to intervention

\begin{tabular}{|l|}
\hline \multicolumn{2}{|c|}{$3 \mathrm{M}+\mathrm{CPP}$} \\
\hline 3 treated \\
2 random CycEV \\
1 CycEV (center pref) \\
$\Rightarrow$ no events
\end{tabular}

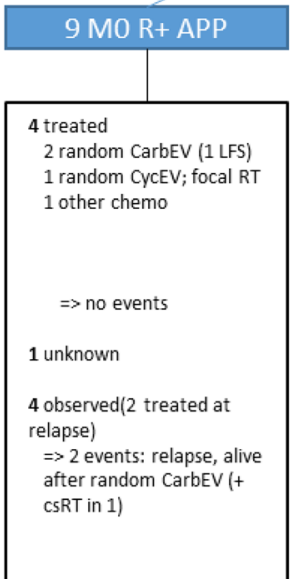

\begin{tabular}{|l|}
\hline \multicolumn{1}{|c|}{$5 \mathrm{M}+\mathrm{APP}$} \\
\hline treated \\
2 random CarbEV; cs RT \\
1 random CycEV \\
1 random (other) \\
1 other (center pref) \\
$\Rightarrow 2$ events
\end{tabular}

\begin{tabular}{|c|}
\hline \multicolumn{2}{|c|}{57 CPC } \\
\hline 55 treated (6 LFS) \\
20 random CarbEV \\
18 (incl 2 LFS) received CarbEV \\
(+ focal RT in 8, +CSRT in 2) \\
1 CycEV (+ focal RT) \\
1 other (+csRT) \\
$\Rightarrow 10$ events \\
15 random to CycEV, \\
14 (incl 4 LFS) received CycEV \\
(+ focal RT in 5, csRT in 4) \\
1 no chemo (dod before chemo) \\
$\Rightarrow 12$ events \\
22 not random, treated by institut pref. \\
1 alive without treatment \\
$\Rightarrow 11$ events
\end{tabular}

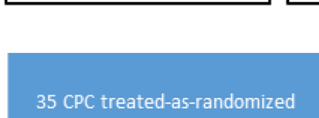

20 CPC CarbEV

15 CPC CYCEV

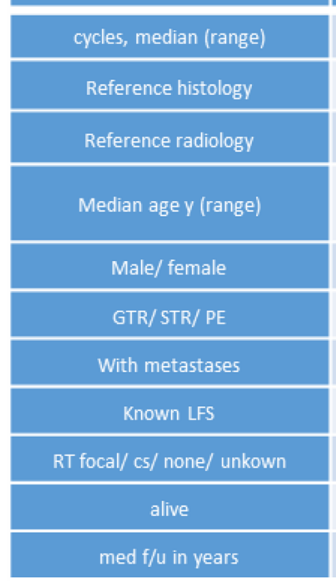

\begin{tabular}{|c|c|}
\hline $6(2-12)$ & $6(3-8)$ \\
\hline 19 & 11 \\
\hline 13 & 5 \\
\hline 3.6 & 2.2 \\
$(0.33-16)$ & $(0.35-9.4)$ \\
\hline $10 / 10$ & $8 / 7$ \\
\hline $9 / 9 / 2$ & $6 / 9 / 0$ \\
\hline 3 & 2 \\
\hline 2 & 4 \\
\hline $9 / 3 / 8$ & $5 / 4 / 5 / 0$ \\
\hline 12 & 6 \\
\hline 6.9 & 4.5 \\
\hline
\end{tabular}


४Fig. 2 a Consort Diagram 1: Enrollment, exclusion, and allocation to surveillance according to protocol risk stratification (low-risk versus high-risk CPT) are shown. Out of 173 screened patients 158 were eligible, with reference histology performed in 138 and reference radiology in 43.87 patients were allocated to registry surveillance. In three reference-reviewed cases, malignant transformation to CPC occurred, indicated by the thin blue arrows resulting in transfer to the intervention allocation; none of these were randomized. 47 of 52 CPP staged M0 underwent surveillance, and 3 events occurred in this group: 1 malignant transformation, 1 relapsed patient treated by surgery, and 1 relapsed treated by surgery and off-study secondary chemotherapy. 5 of $52 \mathrm{CPP}$ staged M0 received primary off-study chemotherapy: 1 to successfully facilitate surgery, 3 at the investigator's discretion because of malignant local pathology, and 1 because of a concurrent malignant glioma. 25 of the 35 APP staged M0R0 underwent surveillance; 5 events occurred in this group: 3 local nonmetastatic relapses that received on-study chemotherapy and additional focal RT in 1; 1 relapse and malignant transformation treated with surgery, off-study chemotherapy and csRT; and 1 subsequent neoplasm (ameloblastoma). 10 of 35 APP staged M0R0 received chemotherapy at the investigator's discretion because of malignant local histology; 2 events occurred in this group: 1 secondary GBM, 1 metastatic relapse. APP Atypical Choroid Plexus Papilloma, CarbEV carboplatin/etoposide/vincristine, $C P C$ Choroid Plexus Carcinoma, $C P T$ Choroid Plexus Tumor, CPP Choroid Plexus Papilloma, csRT craniospinal radiotherapy, $C y c E V$ cyclophosphamide/etoposide/vincristine, dod dead of disease, LFS Li-Fraumeni Syndrome, $M+$ presence of metastasis, $M O$ no metastasis, pref preference, $R+$ residual tumor (partial resection or biopsy), random randomized, $R O$ no residual tumor after tumor surgery, $R T$ radiotherapy. b Consort Diagram 2: Allocation to Intervention. Diagram shows patient allocation to treatment intervention according to protocol risk stratification. $3 \mathrm{CPP}$ staged $\mathrm{M}+$ received primary chemotherapy, 2 randomized for $\mathrm{CycEV}$, 1 received off-study CycEV; no events occurred in this group. 9 APP were staged M0R+, 3 received study-chemotherapy, with additional focal RT in one, 1 received off-study chemotherapy; there were no events in this group. 4 APP staged MOR + were observed at the investigator's discretion; there was one local relapse treated with chemotherapy alone, and one metastatic relapse treated with chemo and csRT. 5 APP staged M+ were all treated with chemotherapy; three received randomized chemo, and two received off-study chemotherapy. Two events occurred in this group (PD). 57 CPC, including three secondary CPC after malignant transformation, were dispositioned to intervention. 1 patient died before chemotherapy; 1 patient is alive without non-surgical treatment. The intention-to-treat analysis comprises $35 \mathrm{CPC}$ as-intended (CarbEV 20, CycEV 15). Relevant demographic variables were distributed homogeneously, as shown in the bottom text-box. A total of 9 APP (5 at diagnosis and 3 APP at relapse in surveillance) were also treated-as-randomized (CarbEV 6, CycEV 3)

radiotherapy ( $60 \%$ versus $64 \%)$; median age was higher in CarbEV (3.6 y, 0.22-16) vs CycEV (2.1 y, 0.35-9.4), there were 2 cases with LFS in the CarbEV and 4 in the CycEV arm\%). After two cycles of chemotherapy the response of $17 \mathrm{CPC}$ with incomplete resection was $1 \mathrm{CR}, 4 \mathrm{PR}, 7 \mathrm{SD}, 3$ $\mathrm{PD}$, and $2 \mathrm{NA}$; the ORR $(\mathrm{CR}+\mathrm{PR})$ here was $55 \%$ in CarbEV $(\mathrm{n}=9)$ versus $0 \%$ in CycEV $(\mathrm{n}=8)(\mathrm{p}<0.05$, Fisher Exact Test, treated as randomized group), and none of the $15 \mathrm{com}-$ pletely resected tumors had recurred.

The 5/10 year OS and PFS as per ITT for CarbEV was $73 \% / 51 \%$ and $62 \% / 47 \%$, respectively, with 12 alive, compared to $53 \% / 36 \%$ and $27 \% / 18 \%$, respectively, for CycEV (HR 2.6, p = 0.032 for PFS), with six alive (Fig. 4).

\section{Safety}

Chemotherapy with CarbEV/CycEV was tolerable-within expected range and without treatment-related deaths. Grade 4 toxicity was limited to leukopenia and thrombopenia. All adverse event data are summarized in Supplemental Table 2. Second malignancies were common: 12 subsequent neoplasms were documented in 10 patients (Table 2): one ameloblastoma 10 years after APP; three myeloid malignancies (2.5, 6 and 3.9 years after CPC), one with an additional nephroblastoma; a glioblastoma 4 years after APP, followed by a soft tissue sarcoma in the same patient (died from glioblastoma); a brainstem astrocytoma with a CPP; one rhabdomyosarcoma prior to APP; one epithelioma after CPC (died from CPC); one hemangioma after APP; and one skull base tumor (radiological meningioma/neurinoma) 1.2 years after CPC. All patients with myeloid malignancies died, two of these from treatment-related complications after intensive chemotherapy.

\section{Discussion}

We report here the largest prospective and the only randomized trial for choroid plexus tumors published to date. The long median observation time of 7.3 years is one outstanding feature. Histological grade emerged as the most relevant prognostic factor, and the value of CarbEV was established for choroid plexus carcinoma. Limitations are incomplete reference review for histology and radiology, and incomplete molecular work-up.

CPP are low-grade tumors with a very high OS; however, they do not completely follow all characteristics of a benign tumor. While mostly localized, typically in the fourth ventricle, three were metastatic at the time of diagnosis, two of these confirmed as by reference radiology. All three received primary chemotherapy and are alive without event at $8.4,10$ and 14.4 years, with PR, SD, and CR, respectively, after 2 cycles. Two untreated CPP, one with methylation subclass pediatric $\mathrm{B}$, progressed to $\mathrm{CPC}$, which is a recognized, albeit rare, event [27]. Both patients received salvage treatment but died from PD 3.1 and 9.3 years after primary diagnosis.

In contrast to CPP, half of the patients with CPC died despite intensive treatment (Fig. 3a). The study data solidify known demographics (Table 1): patients were young (median age 2.1 years), without gender predominance, CPC were mostly located in the lateral ventricles, and 3/57 of the available family histories were positive for LFS, which is relevant for counselling and treatment choices [28]. The prevalence of de novo LFS is known to be high in CPC [7], 
Table 2 Patient demographics

\begin{tabular}{|c|c|c|c|c|}
\hline Primary histology & CPP & APP & $\mathrm{CPC}$ & Total \\
\hline Number of patients & 55 & 49 & 54 & 158 \\
\hline Female/male & $26 / 29$ & $24 / 25$ & $27 / 27$ & $77 / 81$ \\
\hline Median age at diagnosis in years (range) & $2.6(0.2-46)$ & $0.7(0.01-13)$ & $2.1(0.3-18)$ & $1.7(0.01-46)$ \\
\hline Pathogenic germline TP53 variation (LFS) & - & 1 & 6 & 7 \\
\hline Screening for LFS performed & - & 2 & 7 & 9 \\
\hline Sotos syndrome & & 1 & & \\
\hline $\begin{array}{l}\text { Median tumor volume in ml (range), num- } \\
\text { ber of patients }\end{array}$ & $\begin{array}{l}38(5-302) \\
7\end{array}$ & $\begin{array}{l}71(11-231) \\
16\end{array}$ & $\begin{array}{l}50(12-415) \\
22\end{array}$ & $\begin{array}{l}53(5-415) \\
45\end{array}$ \\
\hline Primary location: lateral ventricle, $\mathrm{n}(\%)$ & $35(64 \%)$ & $41(84 \%)$ & $51(94 \%)$ & $127(80 \%)$ \\
\hline IIIrd ventricle, $\mathrm{n}(\%)$ & $4(7 \%)$ & $4(8 \%)$ & $1(2 \%)$ & $9(6 \%)$ \\
\hline IVth ventricle, $\mathrm{n}(\%)$ & $14(26 \%)$ & $3(6 \%)$ & $2(4 \%)$ & $19(12 \%)$ \\
\hline Other (IIIrd + IVth; CPA) & $2(3 \%)$ & $1(2 \%)$ & & $3(2 \%)$ \\
\hline Primary metastases, $\mathrm{n}(\%)$ & $3(6 \%)$ & $5(10 \%)$ & $11(20 \%)$ & $19(12 \%)$ \\
\hline $\begin{array}{l}\text { Subsequent neoplasms } \\
\text { *multiple neoplasm in same patient } \\
\text { LFS confirmed by testing } \\
\text { [n] number of treatment exposures prior to } \\
\text { first subsequent neoplasm }\end{array}$ & 1 brainstem glioma [0] & $\begin{array}{l}1 \text { ameloblastoma [0] } \\
1 \mathrm{GBM} * \& 1 \mathrm{STS} *[2] \\
1 \mathrm{RMS}[2] \\
1 \text { hemangioma [0] }\end{array}$ & $\begin{array}{l}1 \text { AML/MDS [3] } \\
1 \text { AML/MDS [2] } \\
1 \mathrm{AML}^{*} \& 1 \text { nephroblas- } \\
\text { toma* [2] } \\
1 \text { epithelioma [4] } \\
1 \text { skull base tumor (sus- } \\
\text { pected meningioma/neuri- } \\
\text { noma) [2] }\end{array}$ & 12 in 10 patients \\
\hline
\end{tabular}

For medium tumor volume calculations, the ellipsoid volume formula was used: $4 / 3 \pi[\mathrm{A} / 2 \times \mathrm{B} / 2 \times \mathrm{C} / 2]$ ), where $\mathrm{A}$, B and $\mathrm{C}$ are the maximum dimensions in the standard planes: axial (cranio-caudal, A), coronal (transverse, B) and sagittal (anteroposterior), results corresponded well with the abridged ellipsoid formula $(1 / 2(\mathrm{~A} \times \mathrm{B} \times \mathrm{C}))$ as used by the SIOPE Imaging protocol for patients in European SIOP Brain Tumour Studies. In 27 of 45 tumor volumes calculations reference radiology was available

APP Atypical Choroid Plexus Papilloma, CPA cerebellopontine angle, CPC Choroid Plexus Carcinoma, CPP Choroid Plexus Papilloma, GBM glioblastoma multiforme, LFS Li-Fraumeni Syndrome, STS soft tissue sarcoma, *multiple neoplasms in the same patient, 'LFS confirmed by molecular analysis, [n] number of treatment exposures before first subsequent neoplasm, chemotherapy and radiotherapy are counted separately

but due to limitations of the study this could not be fully addressed. Among the detected TP53-germline mutations, one novel complex deletion was identified; the others confirmed previous listings in COSMIC and IARC TP53. The occurrence of an APP in Sotos syndrome described here is a novel finding, expanding the spectrum of this NSDI-related over-growth and tumor-predisposition [29].

Staining for p53 in this study correlated with histology: all CPT with a labeling index $>30 \%$ were CPC. However, this finding was without independent prognostic relevance, apparently contradicting previous reports [30]. The discrepancy might be explained by the integration of histological grade in this analysis (without the covariate, p53 was a negative prognostic variable in this study as reported in others), or by the laboratory technique. Two CPC with underlying LFS had absent staining for p53. Taken together, the data show the limitations of using p53 immunohistochemistry for informing treatment stratification.

This study expands findings from our previous analysis of APP patients [20]. PFS and OS was significantly better for APP patients younger than 2 years at diagnosis (Fig. 3c, d). However, as mitoses are a primary distinguishing feature for this classification, and mitoses are more common in all tissues of infants, the finding might rather reflect the definition of the histological classification, rather than a deep biological principle in choroid plexus tumors [20, 31]. Deferring adjuvant treatment may be justified in select infants with APP and residual tumor [32].

In contrast to common belief [11, 22, 23], this prospective study did not confirm the impact of complete resection in CPC. This is likely the result of improved non-surgical treatment, and the data advocate for staged surgery in the context of comprehensive treatment concepts.

The use of chemotherapy in the treatment of choroid plexus tumors has increased since CPT-SIOP-2000 was designed [17, 21, 33-40] (Table 3). The treatment intensity of many of these protocols is higher than CPT-SIOP-2000, the patient numbers smaller, and the outcome similar [17, 35, 39]. There is no FDA-approved pharmacologic agent that is specific for CPT. A quantitative literature review comparing chemotherapeutic agents suggested benefit of etoposide, carboplatin, cyclophosphamide and vincristine, while similar suggestive evidence was absent for cisplatin, procarbazine and ifosfamide [25]. Since then, methotrexate has been added to the spectrum $[19,33,34,37]$. CPT-SIOP-2000 adds evidence in support of the use of carboplatin (CarbEV) 
Fig. 3 Overall survival (a) and event free survival (b) of all 158 patients registered to CPT-SIOP-2000 by histology. Pathology central review was missing in 20 patients: $5 \mathrm{CPP}$, 3 APP, 12 CPC. 4 of these 12 non-referenced CPC were randomized and treated with $\mathrm{CycEV}$ and one was treated with CarbEV; 1 of 3 nonreferenced APP was randomized and treated in CarbEV. Three patients with malignant transformation that was detected at surgery for relapse are included here with their histology grading at primary diagnosis. This has particular impact on the CPP curves. Two patients with an original diagnosis of $\mathrm{CPP}$ had an increase in tumor grade before treatment was initiated, and died later. If the curves were generated taking only the histology at treatment start into account, then there would be no deaths in the CPP curve. One patient with APP also had malignant transformation. Age effect for Overall Survival (c) and Progression Free Survival (d) in 49 patients with APP, pathology central review missing in 3 APP. APP Atypical Choroid Plexus Papilloma, $C P C$ Choroid Plexus Carcinoma; CPP Choroid Plexus Papilloma, $H R$ Hazard Ratio, CI Confidence Interval (a) Overall Survival ( $n=158$ CPT)

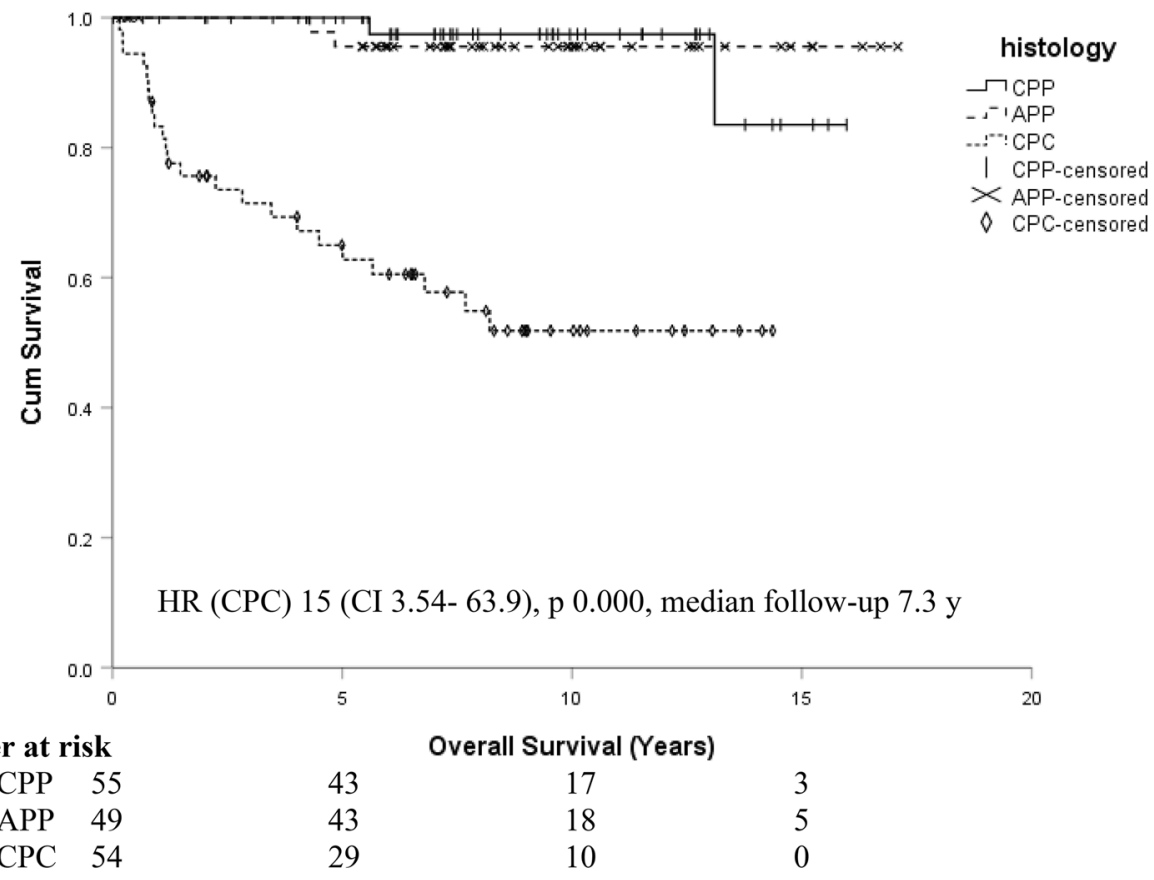

(b) Event Free Survival ( $n=158$ CPT)

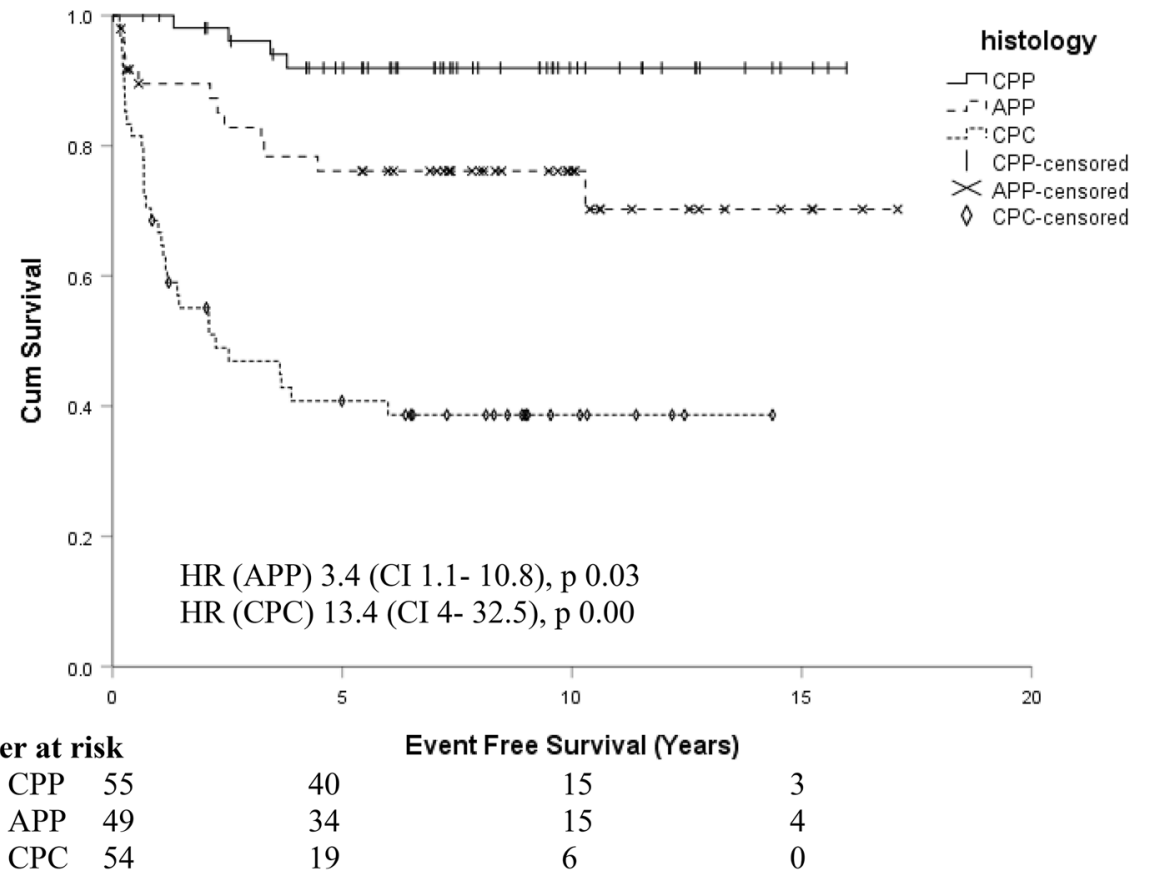

to achieve superior efficacy (significant for PFS, but not OS) compared to cyclophosphamide (CycEV), however the randomization numbers were low. Long recruitment time and small numbers of randomized patients are potential weakness in the study.

The efficacy of irradiation has been suggested in retrospective analyses $[22,23]$. This study confirmed a trend toward longer survival. However, assignment of irradiation remains constrained due to the well-known late neuropsychological sequelae in younger children. Furthermore, particularly in the context of LFS, second malignancies remain a concern. A recent literature review was inconclusive with respect to specific indications for chemotherapy and radiotherapy [13]. 
Fig. 3 (continued) (c) Overall Survival ( $n=49$ APP)

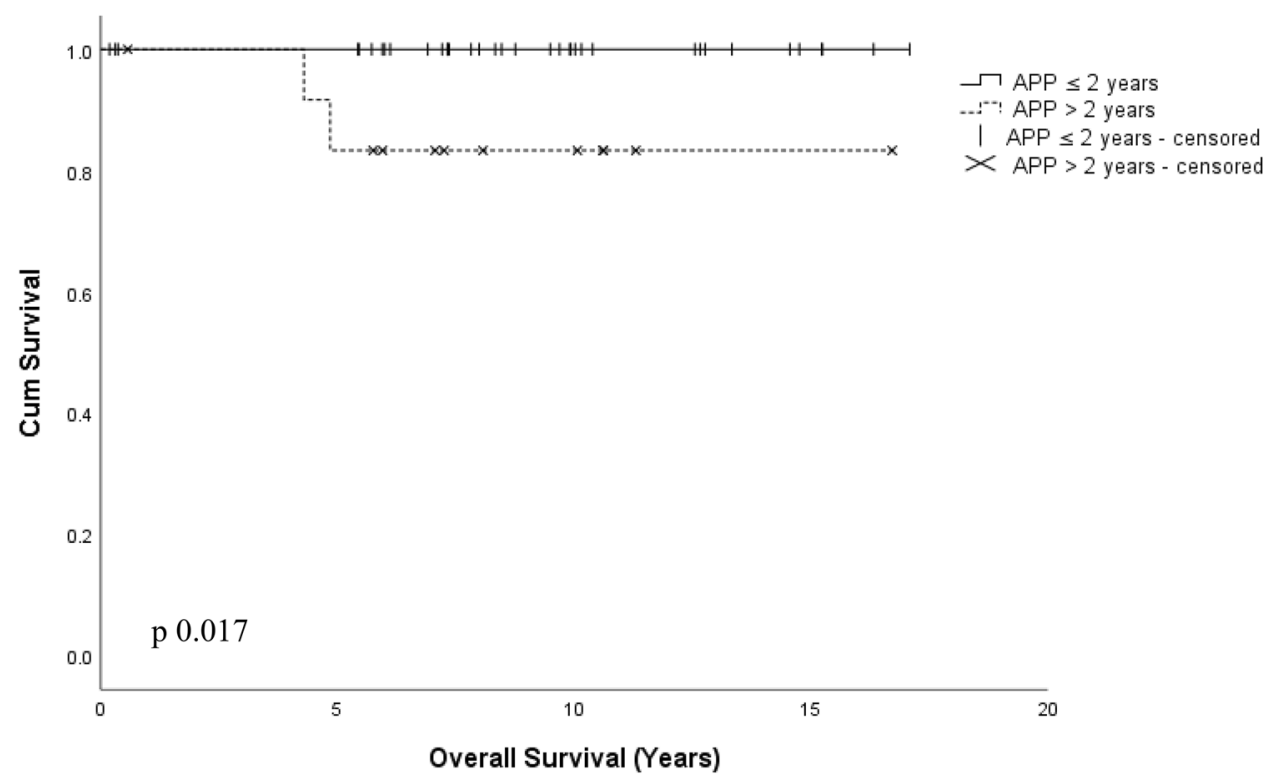

(d) Progression Free Survival ( $n=49$ APP)

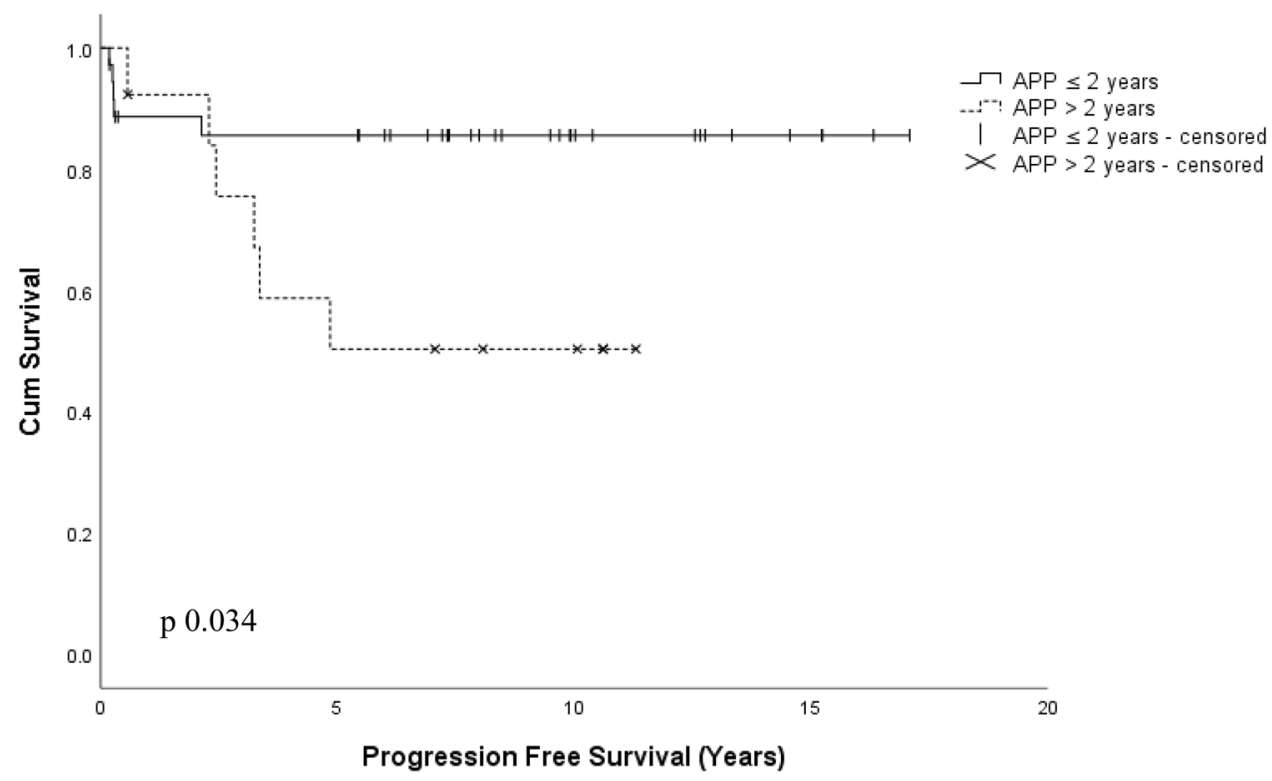

Establishing a treatment algorithm as guidance was a major objective of the CPT-SIOP-2000 study, and the algorithm developed was widely followed in the international pediatric neuro-oncology community. Comparing the overall outcome of this study to the original literature analysis suggests a benefit of a structured algorithm in that the 2-year survival rate in the historical data collection was only half of what was found in CPT-SIOP-2000 [15, 19, 21, 23, 25]. Subsequent guidelines were more detailed and included response to treatment and LFS status [28, 30].

\section{Conclusion}

CPT-SIOP-2000 demonstrates the feasibility of an international randomized clinical trial. CarbEV is effective and tolerable when nested in a multidisciplinary guideline framework. The robust findings of this study add longterm survival data as a benchmark for future intervention, and will help design risk-stratified guidelines. 
Fig. 4 Overall survival (a) and progression free survival (b) by chemotherapy arm for 35 CPC patients as per intention-to-treat, CarbEV-arm $(n=20)$ or CycEV$\operatorname{arm}(n=15)$. Pathology central review missing in 5 CPC.

Results for treated-as-randomized (CarbEV n $=18$; CycEV $\mathrm{n}=14$ are very similar)

\section{(a) Overall Survival ( $\mathrm{n}=35$ CPC treated-as-intended)}

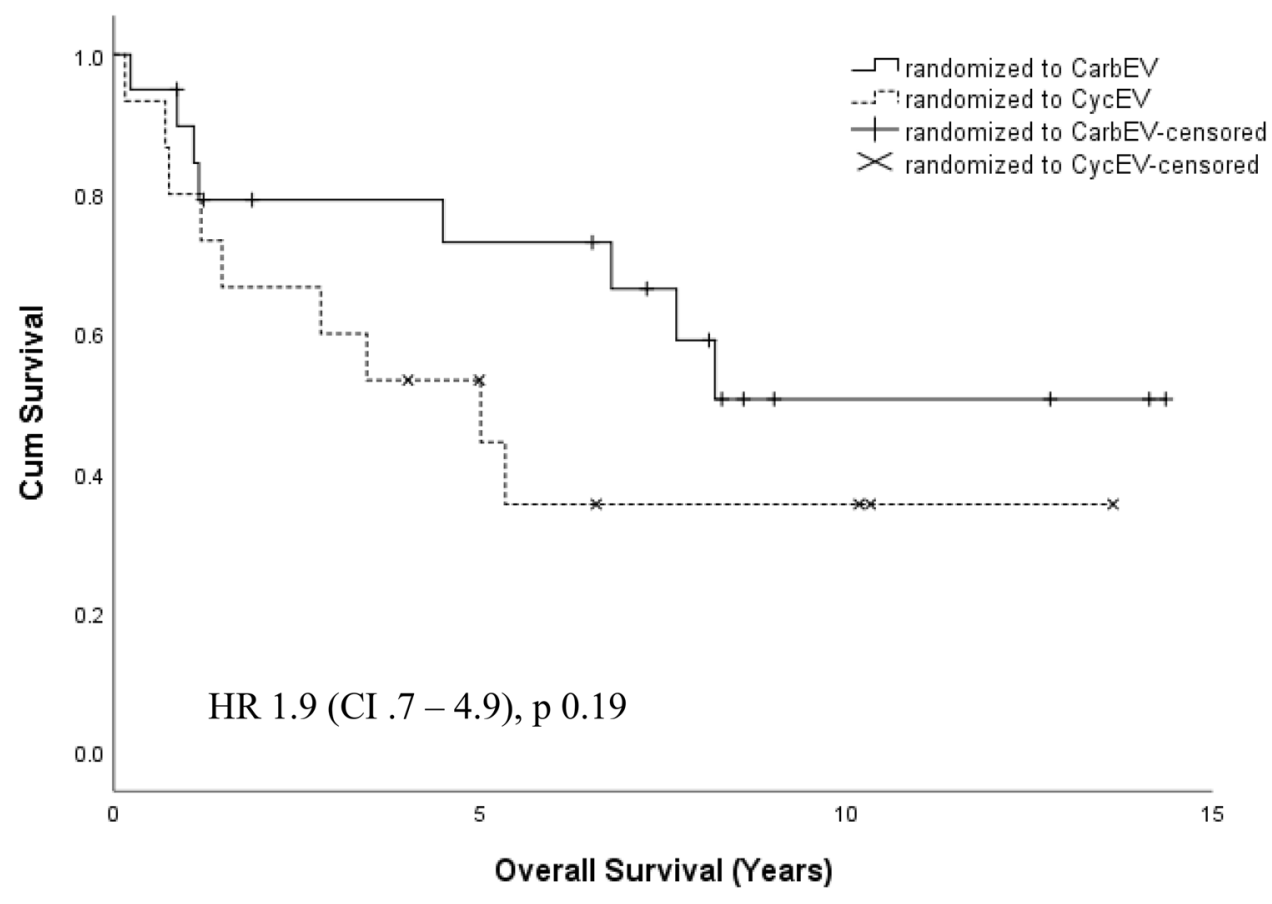

(b) Progression Free Survival ( $n=35$ CPC, treated-as-intended)

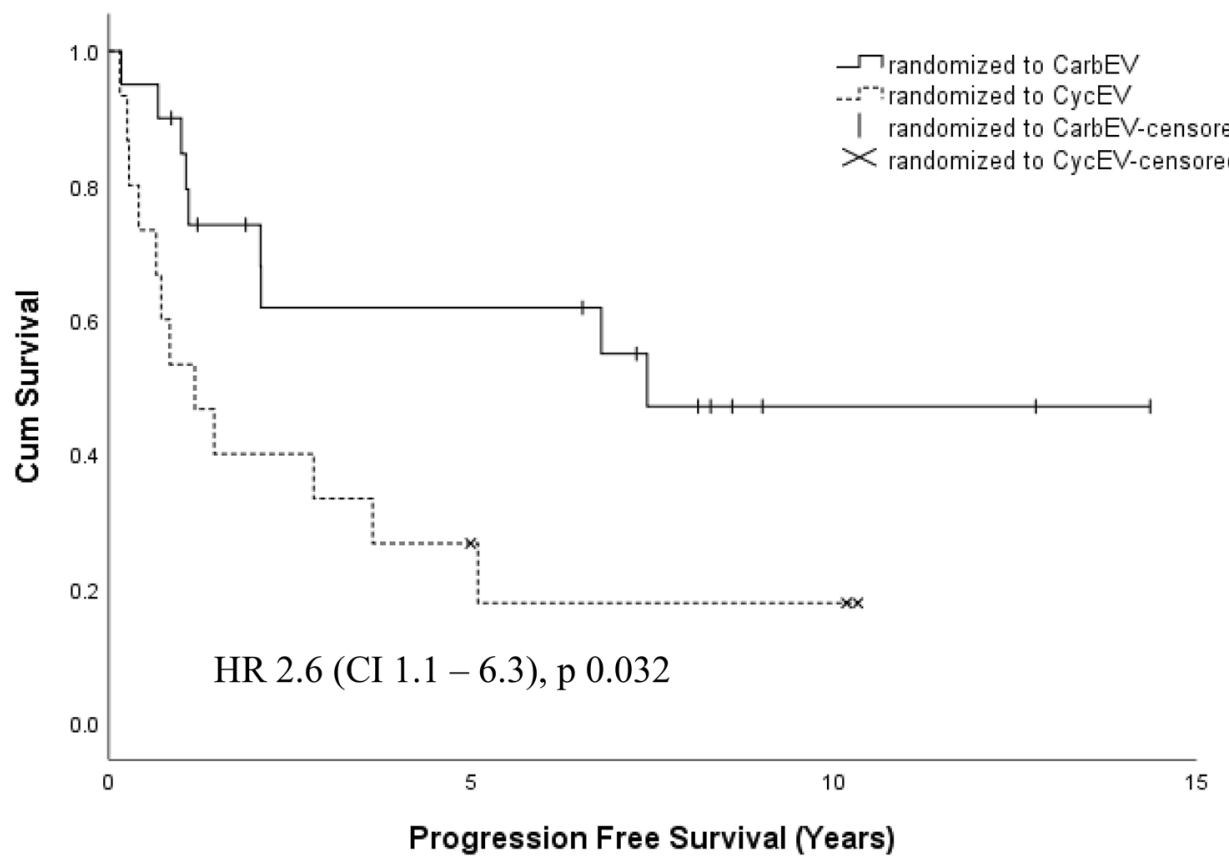


Table 3 Published studies on CPC and outcome

\begin{tabular}{|c|c|c|c|c|c|}
\hline References & $\mathrm{n}$ CPC & Chemotherapy & $\begin{array}{l}\text { Outcome } \\
\text { 5y EFS/PFS }\end{array}$ & $\begin{array}{l}\text { Outcome } \\
5 y \text { OS }\end{array}$ & Comments \\
\hline $\begin{array}{l}\text { CPT-SIOP-2000 } \\
\text { (this publication) }\end{array}$ & 57 & $\begin{array}{l}\text { CarbEV/CycEV, and } \\
\text { other (including registry } \\
\text { patients) }\end{array}$ & $41 \% \mathrm{EFS}$ & $65 \%$ OS (med f/u 6.0 y) & $\begin{array}{l}12 \text { alive RT-free; } 5 \text { alive with } \\
\text { RT at relapse; } 6 \text { LFS }\end{array}$ \\
\hline Liu (2021) (SJYC07) [17] & 13 & $\begin{array}{l}\text { HDMTX/VCR/Cis/Cy/ } \\
\text { (VBL) }\end{array}$ & $61 \%$ PFS & $68 \%$ & 8 alive ( 3 with RT); 4 LFS \\
\hline Siegfried (2017) [19] & 22 & $\begin{array}{l}\text { CarbEV/ VEC/ ICE; BB- } \\
\text { SFOP }\end{array}$ & $25 \%$ EFS & $64.7 \%$ & $\begin{array}{l}\mathrm{RT} \text { in } 9 ; 5 \text { alive } \mathrm{RT} \text {-free, } 1 \\
\mathrm{XRT} \text { at relapse }\end{array}$ \\
\hline $\begin{array}{l}\text { Bahar (2017); Cleveland } \\
\text { Clinic [30] }\end{array}$ & 7 & $\begin{array}{l}\text { SIOP } 2009 \text { CarbEV/ } \\
\text { CycEV/IT/ HDMTX }\end{array}$ & $\begin{array}{l}3 \text { relapse } \\
\text { (all salvaged: } \\
\text { CSRT and } \\
\text { chemo) }\end{array}$ & $100 \%($ med f/u 5y) & $\begin{array}{l}1 \text { adult (transformed CPP), } \\
\text { med AAD } 4.5 \mathrm{y}, 2 \mathrm{M}+\text {, RT } \\
\text { in } 5 \text { ( } 3 \text { at relapse) }\end{array}$ \\
\hline $\begin{array}{l}\text { Zaky (2015); } \\
\text { HS I-III [31] }\end{array}$ & 12 & HS I-III & $38 \%$ PFS & $\begin{array}{l}62 \% \text { OS } \\
5 \text { alive RT-free, } 1 \mathrm{RT} \text { at } \\
\text { relapse }\end{array}$ & $\begin{array}{l}\text { RT in } 5 \text { ( } 4 \text { at relapse, } 1 \text { focal } \\
\text { RT at relapse) }\end{array}$ \\
\hline Dudley (2015); SEER [6] & 95 & & & $\begin{array}{l}60 \% \text { OS (med f/u } \\
40 \text { months) }\end{array}$ & $\begin{array}{l}\text { RT in } 16 \% \\
\text { GTR and RRT ns }\end{array}$ \\
\hline Koh (2014); Seoul [32] & 8 & $\begin{array}{l}\text { Carb/Cis/Cy/Ifo/VCR/ } \\
\text { VP16; } 4 \text { HDCT }\end{array}$ & $2 \mathrm{y}$ PFS $0 \%$ & 2 y OS $42 \%$ & $\begin{array}{l}\text { RT in } 4 ; 3 \text { survived (med f/u } \\
1.5 \mathrm{y}) \\
\text { all HDCT, } 2 \text { foc RT }\end{array}$ \\
\hline $\begin{array}{l}\text { Bettegowda (2012); Johns } \\
\text { Hopkins [33] }\end{array}$ & 7 & not detailed & & $\begin{array}{l}71 \% \text { ( } 5 \text { of } 7 \text { patients } \\
\text { survived) }\end{array}$ & 6 chemo, 3 RT \\
\hline $\begin{array}{l}\text { Grundy (2010); UKCCSG } \\
\text { [34] }\end{array}$ & 15 & Carb/VCR/Cis/MTX & $21.7 \% \mathrm{EFS}$ & $21.5 \% \mathrm{OS}$ & $\begin{array}{l}\text { ph II trial, 11/14 PD on } \\
\text { chemo; } \\
\text { no RT until PD; } 4 \text { alive } \\
\text { RT-free }\end{array}$ \\
\hline $\begin{array}{l}\text { Lafay-Cousin (2010); Sick- } \\
\text { kids [15] }\end{array}$ & 12 & ICE & $53.3 \%$ PFS & $74.1 \%$ OS & $\begin{array}{l}\text { all survivors had GTR/ NTR } \\
\text { and RT-free; } 1 \text { GTR and } \\
\text { HDCT at relapse) } \\
\text { RT in } 3 \text { at relapse/residual }\end{array}$ \\
\hline Fouladi (2009) [37] & 5 & Carbo/Cy/VP16 & $60 \%$ PFS & $80 \%$ OS & $\begin{array}{l}\text { ph II, } 1 \mathrm{M}+\text {, all GTR, RT } \\
\text { for } \mathrm{M}+\text { or PD; } 1 \mathrm{DOD}, 1 \\
\text { died SNL }\end{array}$ \\
\hline $\begin{array}{l}\text { Geyer (2005); CCG } 9921 \\
\text { [35] }\end{array}$ & 9 & $\begin{array}{l}\text { VCR/Cis, Cy/VP16; Carb/ } \\
\text { Ifo/VP16; VCR/VP16, } \\
\text { Carbo/VP16 }\end{array}$ & $\begin{array}{l}33 \% \\
7 \mathrm{PD}\end{array}$ & $\begin{array}{l}63 \%(3 \mathrm{y}) \\
4 \text { patients died }\end{array}$ & $\begin{array}{l}\text { ph II random } \\
\text { no upfront RT }\end{array}$ \\
\hline Chow (1999); SJCRH [36] & 10 & Cy/VP16/VCR/Cis, Carbo & $3 \mathrm{PD}$ & $\begin{array}{l}3 \text { alive with RT } \\
2 \text { died }\end{array}$ & RT in 5 (3 at relapse) \\
\hline
\end{tabular}

$A A D$ age at diagnosis, Carb carboplatin, Cis cisplatin, $c s R T$ craniospinal RT, $C y$ cyclophosphamide, DOD dead of disease, GTR gross total resection, HDMTX high-dose methotrexate, $H S$ Head Start, ICE ifosfamide, carboplatin, etoposide, Ifo ifosfamide, $M+$ metastatic, med flu median follow-up, $N T R$ near total resection; $P D$ progressive disease, $R T$ radiotherapy, $S N L$ secondary neoplasm, $V B L$ vinblastine; $V C R$ vincristine; $V E C$ vinctistine/etoposide/cyclophosphamide; $V P 16$ etoposide, $y$ year

Supplementary Information The online version contains supplementary material available at https://doi.org/10.1007/s11060-021-03942-0.

Acknowledgements We want to thank the patients, parents and investigators for enrolling and providing data (Supplemental Table 4), Brigitte Wrede and Stefan Hartung for managing the study and registry, and Peter Thall and Richard Sposto for statistical support, as well as David Ellison, Martin Hasselblatt, Werner Paulus and Torsten Pietsch for reference neuropathology review. The Choroid Plexus Tumor study was, and the registry currently is, supported by the Deutsche Kinderkrebsstiftung DKKS (German childhood Cancer Foundation). Jonathan Finlay and Rejin Kebudi were the Data Monitors for this study. The European CPT collaboration is ongoing with further registries, as well as guidelines.
Author contributions JEW: Conceptualization, Methodology, Investigation, Funding Acquisition, Data Curation, Resources (Patients), Formal Analysis, Writing Original Draft, Writing Review \& Edition, Revision. SVG: Participation in Conceptualization, Resources (Patients), Formal Analysis, Validation, Writing Original Draft, Writing Review \& Edition, Revision. TK: Participation in Conceptualization, Resources (Patients), Writing Review \& Edition. BD: Participation in Conceptualization, Resources (Patients), Writing Review \& Edition. RK: Participation in Conceptualization, Participation in Data Monitoring Committee, Resources (Patients), Writing Review \& Edition. BT: Resources (Radiation Review), Writing Review \& Edition. MG: Participation in Conceptualization, Resources (Patients), Writing Review \& Edition. JS: Participation in Conceptualization, Resources (Patients), Writing Review \& Edition. GNF: Resources (Pathology), Writing Review \& 
Edition. BB: Resources (Radiology), Funding Acquisition, Writing Review \& Edition. URK: Data Curation, Funding Acquisition, Formal Analysis, Validation, Resources (Patients), Writing-Original Draft, Writing-Review \& Editing, Visualization, Revision.

Funding Open Access funding enabled and organized by Projekt DEAL. The Choroid Plexus Tumor study was (JEW), and the registry currently is (BB, UK), supported by the Deutsche Kinderkrebsstiftung DKKS (German childhood Cancer Foundation).

Data availability Not applicable.

\section{Declarations}

Conflict of interest All authors declare not to have any relevant financial or non-financial conflict of interest with this work.

Open Access This article is licensed under a Creative Commons Attribution 4.0 International License, which permits use, sharing, adaptation, distribution and reproduction in any medium or format, as long as you give appropriate credit to the original author(s) and the source, provide a link to the Creative Commons licence, and indicate if changes were made. The images or other third party material in this article are included in the article's Creative Commons licence, unless indicated otherwise in a credit line to the material. If material is not included in the article's Creative Commons licence and your intended use is not permitted by statutory regulation or exceeds the permitted use, you will need to obtain permission directly from the copyright holder. To view a copy of this licence, visit http://creativecommons.org/licenses/by/4.0/.

\section{References}

1. Kaatsch P GD, Spix C (2019) German Childhood Cancer Registry-Annual Report 2018 (1980-2017). https://www.kinderkreb sregister.de/dkkr-gb/latest-publications/annual-reports.html?L=1.

2. Louis DN, Perry A, Wesseling P, Brat DJ, Cree IA, FigarellaBranger D, Hawkins C, Ng HK, Pfister SM, Reifenberger G, Soffietti R, von Deimling A, Ellison DW (2021) The 2021 WHO Classification of Tumors of the Central Nervous System: a summary. Neuro Oncol 23:1231-1251. https://doi.org/10.1093/neuonc/noab106

3. Thomas C, Sill M, Ruland V, Witten A, Hartung S, Kordes U, Jeibmann A, Beschorner R, Keyvani K, Bergmann M, Mittelbronn M, Pietsch T, Felsberg J, Monoranu CM, Varlet P, Hauser P, Olar A, Grundy RG, Wolff JE, Korshunov A, Jones DT, BewerungeHudler M, Hovestadt V, von Deimling A, Pfister SM, Paulus W, Capper D, Hasselblatt M (2016) Methylation profiling of choroid plexus tumors reveals 3 clinically distinct subgroups. Neuro Oncol 18:790-796. https://doi.org/10.1093/neuonc/nov322

4. Capper D, Jones DTW, Sill M, Hovestadt V, Schrimpf D, Sturm D, Koelsche C, Sahm F, Chavez L, Reuss DE, Kratz A, Wefers AK, Huang K, Pajtler KW, Schweizer L, Stichel D, Olar A, Engel NW, Lindenberg K, Harter PN, Braczynski AK, Plate KH, Dohmen H, Garvalov BK, Coras R, Holsken A, Hewer E, Bewerunge-Hudler M, Schick M, Fischer R, Beschorner R, Schittenhelm J, Staszewski O, Wani K, Varlet P, Pages M, Temming P, Lohmann D, Selt F, Witt H, Milde T, Witt O, Aronica E, Giangaspero F, Rushing E, Scheurlen W, Geisenberger C, Rodriguez FJ, Becker A, Preusser M, Haberler C, Bjerkvig R, Cryan J, Farrell M, Deckert M, Hench J, Frank S, Serrano J, Kannan K, Tsirigos A, Bruck W, Hofer S, Brehmer S, Seiz-Rosenhagen M,
Hanggi D, Hans V, Rozsnoki S, Hansford JR, Kohlhof P, Kristensen BW, Lechner M, Lopes B, Mawrin C, Ketter R, Kulozik A, Khatib Z, Heppner F, Koch A, Jouvet A, Keohane C, Muhleisen H, Mueller W, Pohl U, Prinz M, Benner A, Zapatka M, Gottardo NG, Driever PH, Kramm CM, Muller HL, Rutkowski S, von Hoff K, Fruhwald MC, Gnekow A, Fleischhack G, Tippelt S, Calaminus G, Monoranu CM, Perry A, Jones C, Jacques TS, Radlwimmer B, Gessi M, Pietsch T, Schramm J, Schackert G, Westphal M, Reifenberger G, Wesseling P, Weller M, Collins VP, Blumcke I, Bendszus M, Debus J, Huang A, Jabado N, Northcott PA, Paulus W, Gajjar A, Robinson GW, Taylor MD, Jaunmuktane Z, Ryzhova M, Platten M, Unterberg A, Wick W, Karajannis MA, Mittelbronn M, Acker T, Hartmann C, Aldape K, Schuller U, Buslei R, Lichter P, Kool M, Herold-Mende C, Ellison DW, Hasselblatt M, Snuderl M, Brandner S, Korshunov A, von Deimling A, Pfister SM (2018) DNA methylationbased classification of central nervous system tumours. Nature 555:469-474. https://doi.org/10.1038/nature26000

5. Pienkowska M, Choufani S, Turinsky AL, Guha T, Merino DM, Novokmet A, Brudno M, Weksberg R, Shlien A, Hawkins C, Bouffet E, Tabori U, Gilbertson RJ, Finlay JL, Jabado N, Thomas C, Sill M, Capper D, Hasselblatt M, Malkin D (2019) DNA methylation signature is prognostic of choroid plexus tumor aggressiveness (vol 11, 117, 2019). Clin Epigenetics. https://doi.org/10. 1186/s13148-019-0737-7

6. Thomas C, Metrock K, Kordes U, Hasselblatt M, Dhall G (2020) Epigenetics impacts upon prognosis and clinical management of choroid plexus tumors. J Neurooncol 148:39-45. https://doi.org/ 10.1007/s11060-020-03509-5

7. Tinat J, Bougeard G, Baert-Desurmont S, Vasseur S, Martin C, Bouvignies E, Caron O, Bressac-de Paillerets B, Berthet P, Dugast C, Bonaiti-Pellie C, Stoppa-Lyonnet D, Frebourg T (2009) 2009 version of the Chompret criteria for Li Fraumeni syndrome. J Clin Oncol 27: e108-109; author reply e110. https://doi.org/10.1200/ JCO.2009.22.7967

8. Dudley RW, Torok MR, Gallegos D, Liu AK, Handler MH, Hankinson TC (2015) Pediatric choroid plexus tumors: epidemiology, treatments, and outcome analysis on 202 children from the SEER database. J Neurooncol 121:201-207. https://doi.org/10. 1007/s11060-014-1628-6

9. Hosmann A, Hinker F, Dorfer C, Slave I, Haberler C, Dieckmann K, Knosp E, Czech T (2019) Management of choroid plexus tumors-an institutional experience. Acta Neurochir (Wien) 161:745-754. https://doi.org/10.1007/s00701-019-03832-5

10. Konar SK, Kandregula S, Beniwal M, Sadashiva N, Patel KRK, Nagesh M, Rao K, Vikas V, Raj P, Shashidhar A, Uppar AM, Shukla D, Indira Devi B, Srinivas D (2021) Management of choroid plexus tumours: a comprehensive study from a tertiary hospital. Clin Neurol Neurosurg 201:106454. https://doi.org/10.1016/j. clineuro.2020.106454

11. Wrede B, Liu P, Ater J, Wolff JE (2005) Second surgery and the prognosis of choroid plexus carcinoma-results of a meta-analysis of individual cases. Anticancer Res 25:4429-4433

12. Gaddi MJS, Lappay JI, Chan KIP, Pascual JSG, Salonga AEM (2021) Pediatric choroid plexus papilloma arising from the cerebellopontine angle: systematic review with illustrative case. Childs Nerv Syst 37:799-807. https://doi.org/10.1007/ s00381-020-04896-w

13. Tavallaii A, Keykhosravi E, Rezaee H, Kianbakht C (2020) Role of available adjuvant therapies following surgical resection of atypical choroid plexus papilloma-a systematic review and pooled analysis. Neurooncol Adv 2:vdaa139. https://doi.org/10.1093/ noajnl/vdaa139

14. Ferreira Furtado LM, Da Costa Val Filho JA, Moura de Sousa C, Dantas F, Holliday JB (2020) Selective neuroendoscopic resection of the choroid plexus as an alternative technique for optimizing 
the standard endoscopic approach to hydrocephalus. Cureus 12:e11618. https://doi.org/10.7759/cureus.11618

15. Wrede B, Liu P, Wolff JE (2007) Chemotherapy improves the survival of patients with choroid plexus carcinoma: a meta-analysis of individual cases with choroid plexus tumors. J Neurooncol 85:345-351. https://doi.org/10.1007/s11060-007-9428-x

16. Lafay-Cousin L, Keene D, Carret AS, Fryer C, Brossard J, Crooks B, Eisenstat D, Johnston D, Larouche V, Silva M, Wilson B, Zelcer S, Bartels U, Bouffet E (2011) Choroid plexus tumors in children less than 36 months: the Canadian Pediatric Brain Tumor Consortium (CPBTC) experience. Childs Nerv Syst 27:259-264. https://doi.org/10.1007/s00381-010-1269-9

17. Lafay-Cousin L, Mabbott DJ, Halliday W, Taylor MD, Tabori U, Kamaly-Asl ID, Kulkarni AV, Bartels U, Greenberg M, Bouffet E (2010) Use of ifosfamide, carboplatin, and etoposide chemotherapy in choroid plexus carcinoma. J Neurosurg Pediatr 5:615-621. https://doi.org/10.3171/2010.3.PEDS09354

18. Schneider C, Kamaly-Asl I, Ramaswamy V, Lafay-Cousin L, Kulkarni AV, Rutka JT, Remke M, Coluccia D, Tabori U, Hawkins C, Bouffet E, Taylor MD (2015) Neoadjuvant chemotherapy reduces blood loss during the resection of pediatric choroid plexus carcinomas. J Neurosurg Pediatr 16:126-133. https://doi.org/10. 3171/2014.12.PEDS14372

19. Liu APY, Wu G, Orr BA, Lin T, Ashford JM, Bass JK, Bowers DC, Hassall T, Fisher PG, Indelicato DJ, Klimo P Jr, Boop F, Conklin H, Onar-Thomas A, Merchant TE, Ellison DW, Gajjar A, Robinson GW (2021) Outcome and molecular analysis of young children with choroid plexus carcinoma treated with non-myeloablative therapy: results from the SJYC07 trial. Neurooncol Adv 3:vdaa168. https://doi.org/10.1093/noajnl/vdaa168

20. Wrede B, Hasselblatt M, Peters O, Thall PF, Kutluk T, Moghrabi A, Mahajan A, Rutkowski S, Diez B, Wang X, Pietsch T, Kortmann RD, Paulus W, Jeibmann A, Wolff JEA (2009) Atypical choroid plexus papilloma: clinical experience in the CPTSIOP-2000 study. J Neurooncol 95:383-392. https://doi.org/10. 1007/s11060-009-9936-y

21. Siegfried A, Morin S, Munzer C, Delisle MB, Gambart M, Puget S, Maurage CA, Miquel C, Dufour C, Leblond P, Andre N, Branger DF, Kanold J, Kemeny JL, Icher C, Vital A, Coste EU, Bertozzi AI (2017) A French retrospective study on clinical outcome in 102 choroid plexus tumors in children. J Neurooncol 135:151-160. https://doi.org/10.1007/s11060-017-2561-2

22. Wolff JE, Sajedi M, Coppes MJ, Anderson RA, Egeler RM (1999) Radiation therapy and survival in choroid plexus carcinoma. Lancet 353:2126. https://doi.org/10.1016/s0140-6736(99)01744-4

23. Wolff JE, Sajedi M, Brant R, Coppes MJ, Egeler RM (2002) Choroid plexus tumours. Br J Cancer 87:1086-1091. https://doi.org/ 10.1038/sj.bjc.6600609

24. Faramand A, Kano H, Niranjan A, Atik AF, Lee CC, Yang HC, Mohammed N, Liscak R, Hanuska J, Tripathi M, Kondziolka D, Sheehan J, Mathieu D, Flickinger JC, Lunsford LD (2021) stereotactic radiosurgery for choroid plexus tumors: a report of the international radiosurgery research foundation. Neurosurgery 88:791-796. https://doi.org/10.1093/neuros/nyaa538

25. Berrak SG, Liu DD, Wrede B, Wolff JE (2011) Which therapy works better in choroid plexus carcinomas? J Neurooncol 103:155-162. https://doi.org/10.1007/s11060-010-0372-9

26. Wolff JE, Myles T, Pinto A, Rigel JE, Angyalfi S, Kloiber R (2001) Detection of choroid plexus carcinoma with Tc-99m sestamibi: case report and review of the literature. Med Pediatr Oncol 36:323-325. https://doi.org/10.1002/1096-911X(20010201)36:2\% 3c323::AID-MPO1075\%3e3.0.CO;2-R

27. Yankelevich M, Finlay JL, Gorsi H, Kupsky W, Boue DR, Koschmann CJ, Kumar-Sinha C, Mody R (2021) Molecular insights into malignant progression of atypical choroid plexus papilloma. Cold Spring Harb Mol Case Stud. https://doi.org/10. 1101/mcs.a005272

28. Bahar M, Kordes U, Tekautz T, Wolff J (2015) Radiation therapy for choroid plexus carcinoma patients with Li-Fraumeni syndrome: advantageous or detrimental? Anticancer Res 35:3013-3017

29. Weinberg DN, Papillon-Cavanagh S, Chen H, Yue Y, Chen X, Rajagopalan KN, Horth C, McGuire JT, Xu X, Nikbakht H, Lemiesz AE, Marchione DM, Marunde MR, Meiners MJ, Cheek MA, Keogh MC, Bareke E, Djedid A, Harutyunyan AS, Jabado N, Garcia BA, Li H, Allis CD, Majewski J, Lu C (2019) The histone mark H3K36me2 recruits DNMT3A and shapes the intergenic DNA methylation landscape. Nature 573:281-286. https://doi.org/ 10.1038/s41586-019-1534-3

30. Tabori U, Shlien A, Baskin B, Levitt S, Ray P, Alon N, Hawkins C, Bouffet E, Pienkowska M, Lafay-Cousin L, Gozali A, Zhukova N, Shane L, Gonzalez I, Finlay J, Malkin D (2010) TP53 alterations determine clinical subgroups and survival of patients with choroid plexus tumors. J Clin Oncol 28:1995-2001. https://doi. org/10.1200/JCO.2009.26.8169

31. Jeibmann A, Hasselblatt M, Gerss J, Wrede B, Egensperger R, Beschorner R, Hans VH, Rickert CH, Wolff JE, Paulus W (2006) Prognostic implications of atypical histologic features in choroid plexus papilloma. J Neuropathol Exp Neurol 65:1069-1073. https://doi.org/10.1097/01.jnen.0000240464.26005.90

32. Browne-Farmer C, Hazrati LN, Mamatjan Y, Zadeh G, Dirks P, Rutka J, Malkin D, Bouffet E, Huang A, Tabori U, Ramaswamy V, Bartels U (2021) Paediatric atypical choroid plexus papilloma: is adjuvant therapy necessary? J Neurooncol 155:63-70. https:// doi.org/10.1007/s11060-021-03843-2

33. Bahar M, Hashem H, Tekautz T, Worley S, Tang A, de Blank P, Wolff J (2017) Choroid plexus tumors in adult and pediatric populations: the Cleveland Clinic and University Hospitals experience. J Neurooncol 132:427-432. https://doi.org/10.1007/ s11060-017-2384-1

34. Zaky W, Dhall G, Khatua S, Brown RJ, Ginn KF, Gardner SL, Yildiz VO, Yankelevich M, Finlay JL (2015) Choroid plexus carcinoma in children: the Head Start experience. Pediatr Blood Cancer 62:784-789. https://doi.org/10.1002/pbc.25436

35. Koh EJ, Wang KC, Phi JH, Lee JY, Choi JW, Park SH, Park KD, Kim IH, Cho BK, Kim SK (2014) Clinical outcome of pediatric choroid plexus tumors: retrospective analysis from a single institute. Childs Nerv Syst 30:217-225. https://doi.org/10.1007/ s00381-013-2223-4

36. Bettegowda C, Adogwa O, Mehta V, Chaichana KL, Weingart J, Carson BS, Jallo GI, Ahn ES (2012) Treatment of choroid plexus tumors: a 20-year single institutional experience. J Neurosurg Pediatr 10:398-405. https://doi.org/10.3171/2012.8.PEDS12132

37. Grundy RG, Wilne SH, Robinson KJ, Ironside JW, Cox T, Chong WK, Michalski A, Campbell RH, Bailey CC, Thorp N, Pizer B, Punt J, Walker DA, Ellison DW, Machin D, Children's C, Leukaemia Group Brain Tumour C (2010) Primary postoperative chemotherapy without radiotherapy for treatment of brain tumours other than ependymoma in children under 3 years: results of the first UKCCSG/SIOP CNS 9204 trial. Eur J Cancer 46:120-133. https://doi.org/10.1016/j.ejca.2009.09.013

38. Geyer JR, Sposto R, Jennings M, Boyett JM, Axtell RA, Breiger D, Broxson E, Donahue B, Finlay JL, Goldwein JW, Heier LA, Johnson D, Mazewski C, Miller DC, Packer R, Puccetti D, Radcliffe J, Tao ML, Shiminski-Maher T, Children's Cancer G (2005) Multiagent chemotherapy and deferred radiotherapy in infants with malignant brain tumors: a report from the Children's Cancer Group. J Clin Oncol 23:7621-7631. https://doi.org/10.1200/JCO. 2005.09.095

39. Chow E, Reardon DA, Shah AB, Jenkins JJ, Langston J, Heideman RL, Sanford RA, Kun LE, Merchant TE (1999) Pediatric choroid 
plexus neoplasms. Int J Radiat Oncol Biol Phys 44:249-254. https://doi.org/10.1016/s0360-3016(98)00560-4

40. Fouladi M, Gururangan S, Moghrabi A, Phillips P, Gronewold L, Wallace D, Sanford RA, Gajjar A, Kun LE, Heideman R (2009) Carboplatin-based primary chemotherapy for infants and young children with CNS tumors. Cancer 115:3243-3253. https://doi. org/10.1002/cncr.24362
Publisher's Note Springer Nature remains neutral with regard to jurisdictional claims in published maps and institutional affiliations.

\section{Authors and Affiliations}

\section{Johannes E. Wolff ${ }^{1,2} \cdot$ Stefaan W. Van Gool ${ }^{3}\left(\mathbb{D} \cdot\right.$ Tezer Kutluk $^{4}\left(\mathbb{D} \cdot\right.$ Blanca Diez $^{5}\left(\mathbb{D}^{\circ} \cdot\right.$ Rejin Kebudi $^{6}(\mathbb{D})$

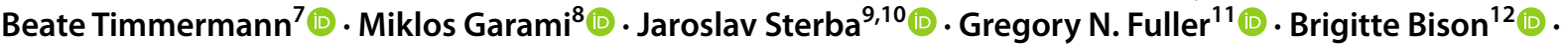 Uwe R. Kordes ${ }^{13}$ (1)}

Johannes E. Wolff

johannesewolff@gmail.com

Stefaan W. Van Gool

vangool@iozk.de

Tezer Kutluk

tezerkutluk@gmail.com

Blanca Diez

bdiez@fleni.org.ar

Rejin Kebudi

rejinkebudi@yahoo.com

Beate Timmermann

Beate.Timmermann@uk-essen.de

Miklos Garami

garami.miklos@med.semmelweis-univ.hu

Jaroslav Sterba

Sterba.Jaroslav@fnbrno.cz

Gregory N. Fuller

gfuller@mdanderson.org

Brigitte Bison

Brigitte.Bison@uk-augsburg.de

1 University of Regensburg, Regensburg, Germany

2 Present Address: Oncology Development, AbbVie, Chicago, IL, USA

3 IOZK Immune Oncological Centre Cologne, Cologne, Germany
4 Department of Pediatric Oncology, Hacettepe University Medical School and Cancer Institute, Ankara, Turkey

5 Neuro Oncology Program, Institute of Neurological Research, FLENI, Buenos Aires, Argentina

6 Pediatric Hematology-Oncology, Oncology Institute, Istanbul University, Istanbul, Turkey

7 Department of Particle Therapy, University Hospital Essen, West German Proton Therapy Centre Essen (WPE), West German Cancer Center (WTZ), German Cancer Consortium (DKTK), Essen, Germany

8 2nd Department of Pediatrics, Semmelweis University, Budapest, Hungary

9 Department of Pediatric Oncology, University Hospital Brno and Faculty of Medicine, Masaryk University, Brno, Czech Republic

10 International Clinical Research Center, St. Anne's University Hospital, Brno, Czech Republic

11 Departments of Neuropathology and Neuroradiology, MD Anderson Cancer Center, Houston, USA

12 Department of Neuroradiology, University Hospital of Augsburg, Augsburg, Germany

13 Department of Pediatric Hematology and Oncology, University Medical Center Hamburg, Hamburg, Germany 